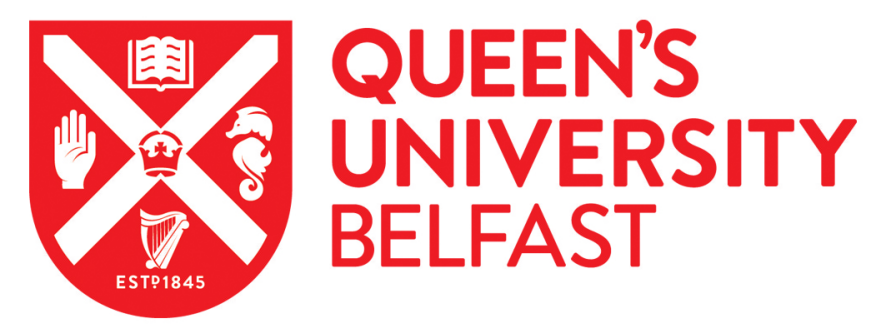

\title{
A study of the kinetic solvent isotope effect on the destruction of microcystin-LR and geosmin using TiO2 photocatalysis
}

Robertson, P. K. J., Bahnemann , D. W., Lawton, L. A., \& Bellu, E. (2011). A study of the kinetic solvent isotope effect on the destruction of microcystin-LR and geosmin using TiO photocatalysis. Applied Catalysis B: Environmental, 108-109, 1-5. https://doi.org/10.1016/j.apcatb.2011307.019

Published in:

Applied Catalysis B: Environmental

Document Version:

Peer reviewed version

Queen's University Belfast - Research Portal:

Link to publication record in Queen's University Belfast Research Portal

Publisher rights

(c) 2011 Elsevier. This manuscript version is made available under the Creative Commons Attribution-NonCommercial-NoDerivs License (http://creativecommons.org/licenses/by-nc-nd/4.0/), which permits distribution and reproduction for non-commercial purposes, provided the author and source are cited.

\section{General rights}

Copyright for the publications made accessible via the Queen's University Belfast Research Portal is retained by the author(s) and / or other copyright owners and it is a condition of accessing these publications that users recognise and abide by the legal requirements associated with these rights.

Take down policy

The Research Portal is Queen's institutional repository that provides access to Queen's research output. Every effort has been made to ensure that content in the Research Portal does not infringe any person's rights, or applicable UK laws. If you discover content in the Research Portal that you believe breaches copyright or violates any law, please contact openaccess@qub.ac.uk. 
A study of Kinetic Solvent Isotope Effect on the Destruction of MicrocystinLR and Geosmin using $\mathrm{TiO}_{2}$ Photocatalysis.

Peter K. J. Robertson ${ }^{\mathrm{a}^{\star}}$, Detlef W. Bahnemann ${ }^{\mathrm{b}}$, Linda A. Lawton ${ }^{\mathrm{a}}$ and Edmund Bellua

a Innovation, Design and Sustainability Research Institute (IDeaS), The Robert Gordon University, Schoolhill, Aberdeen, AB10 1FR, UK

b Institut fuer Technische Chemie, Universitaet Hannover, Callinstrasse 3, D30167 Hannover, Germany

* Corresponding Author phone: +44 1224 263750; fax: +44 1224 262759; e-mail: peter.robertson@rgu.ac.uk 


\begin{abstract}
.
We have previously reported the effectiveness of $\mathrm{TiO}_{2}$ photocatalysis in the destruction of species generated by cyanobacteria, specifically geosmin and microcystin-LR. In this paper we report an investigation of factors which influence the rate of the toxin destruction at the catalyst surface. A primary kinetic solvent isotope effect of approximately 1.5 was observed when the destruction was performed in a heavy water solvent. This is in contrast to previous reports of a solvent isotope effect of approximately 3, however, these studies were undertaken with a different photocatalyst material. The solvent isotope effect therefore appears to be dependent on the photocatalyst material used. The results of the study support the theory that the photocatalytic decomposition occurs on the catalyst surface rather than in the bulk of the solution. Furthermore it appears that the rate determining step is not oxygen reduction as previously reported.
\end{abstract}

\title{
Keywords
}

Photocatalyst, $\mathrm{TiO}_{2}$, microcystin, geosmin, heavy water, drinking water, kinetic solvent isotope effect. 


\section{Introduction.}

In recent years there has been a significant increase in eutrophication of water bodies resulting from human activities such as agriculture. This has unfortunately resulted in promotion of the growth of cyanobacterial species. These cyanobacteria can generate a number of compounds ranging from the non-toxic species geosmin through to highly toxic cyanotoxins such as microcystins. Geosmin (GSM) (figure 1), an alicyclic alcohol, is a semi-volatile compound that is produced by microorganisms in surface waters, namely cyanobacteria and actinomycetes. Geosmin causes undesirable earthy off-flavours in freshwater fish as well as causing major concern for the drinking water industry due to seasonal taste and odour episodes [1]. The problem is exacerbated by the low threshold of detection level of geosmin $\left(0.015 \mu \mathrm{g} \mathrm{L}^{-1}\right)$ by humans [2]. Although non-toxic, the presence of geosmin in drinking water results in consumer rejection and an association with inadequate water quality by the public [3]. The compound's lipophilic nature is also the source of significant problems in aquaculture. Geosmin rapidly accumulates in fish flesh, thereby resulting in poor flavour quality and subsequent delays in harvesting due to rejection of the cultured fish by processors [4]. Off-flavours add $\$ 15$ to $\$ 23$ million annually to catfish production costs in the USA and is a significant problem to aquaculture worldwide [5]. The additional costs are a consequence of the fact that fish contaminated by geosmin are not palatable and therefore cannot be sold. In addition there may be significant cleanup costs also associated with an outbreak of geosmin contamination. Microcystins are hepatoxins released by the 
cyanobacteria microcystis [6], which have caused the deaths of both animals and humans following ingestion of contaminated water $[6,7,8]$. There are over 70 variants of microcystins one of the most common being microcystin-LR (MC-LR) (figure 2) [9]. This compound is a cyclic heptapeptide containing the amino acid 3-amino-9-methoxy-2,6,8-trimethyl-10-phenyldeca-4,6-dienoic acid (adda), with leucine (L) and arginine (A) in the variable positions. Although microcystins are chemically very stable [10] and conventional water treatment processes have so far failed to remove them [10-13], we have previously reported the effectiveness of $\mathrm{TiO}_{2}$ photocatalysis in the destruction of both microcystin-LR and geosmin [1424]. Microcystin was rapidly decomposed using a titanium dioxide photocatalyst with toxicity being eliminated as demonstrated by both brine shrimp and protein phosphatase bioassays $[14,18]$. Furthermore both the photocatalytic destruction and dark adsorption of the toxin to the photocatalyst surface were found to be strongly influence by $\mathrm{pH}$ [19]. Geosmin was also rapidly decomposed using a titanium dioxide photocatalysis with elimination of this molecule achieved within 60 minutes irradiation [20].

Figure 1.

Figure 2.

From our previous work we have demonstrated the critical role of the hydroxyl radical generated by the $\mathrm{TiO}_{2}$ photocatalyst in the destruction of these species 
$[15,21]$. In this paper we have further extended the investigation of the importance of the surface reaction between the photocatalyst and adsorbed water in the photocatalytic oxidation of both these problematic compounds. Furthermore the results provide a further understanding of the processes occurring at the photocatalyst surface that will be equally relevant to a broad range of photocatalytic oxidation processes. This has been achieved by studying the kinetic solvent isotope effect of the photocatalytic reaction. In this process the rate of reaction in water is compared to that achieved in deuterated water $\left(\mathrm{D}_{2} \mathrm{O}\right)$. This results in a change in the reaction rate and may provide aid in interpreting mechanistic processes involved in the reaction under investigation. 


\section{Materials and Methods}

\subsection{Materials.}

Geosmin, (Supelco, Sigma-Aldrich) and titanium dioxide (Hombikat K01/C, Sachtleben Chemie $\mathrm{GmbH}$ ) were used as received. Solutions containing 100 $\mu \mathrm{g}$ $\mathrm{ml}^{-1}$ of microcystin-LR were prepared in each solvent by exhaustive resuspension of freeze-dried MC-LR. The destruction of geosmin and microcystinLR was performed in both Milli-Q water and in $\mathrm{D}_{2} \mathrm{O}(99.9 \%$ atom \%D, SigmaAldrich, UK).

\subsection{Photocatalysis.}

Solutions (20 mL) of GSM mixed with $15 \mathrm{~g}$ Hombikat $\mathrm{K01} / \mathrm{C} \mathrm{TiO}_{2}$ were prepared using D2O and Milli-Q water. These solutions were then illuminated in the presence of air with a xenon UV lamp (400 W UVASpot 400 lamp, Uvalight Technology Ltd; spectral output $330-500 \mathrm{~nm}$ ) situated $30 \mathrm{~cm}$ from the reactor. Reactions were carried out in a glass batch reactor with a constant air flow provided (30 mL min-1 $\pm 5 \%$ ) via the bottom of the reactor (Figure 3). Samples $(200 \mu \mathrm{l})$ were taken at timed intervals of $0,5,10,15,20,25,30,40,50,60,70$, 80, 90 and 100 minutes of illumination and placed into inserts in $4 \mathrm{ml}$ vials and analysed by high performance liquid chromatography (600E powerline gradient module pump with WISP auto sample and 996 photodiode array detector; Waters Ltd., UK) [25]. 
The degradation of MC-LR in Milli-Q water $\left(\sim 100 \mu \mathrm{g} \mathrm{ml}^{-1}\right)$ was also investigated using this method. Samples $(200 \mu l)$ were taken at timed intervals of $0,5,10,15$, $20,25,30,40,50,60,70,80,90$ and 100 minutes of illumination and analysed by high performance liquid chromatography.

Figure 3

\section{Results and Discussion.}

The photocatalytic destruction of geosmin in both Milli-Q $\left(\mathrm{H}_{2} \mathrm{O}\right)$ and heavy water $\left(D_{2} \mathrm{O}\right)$ solvents is shown in Figure 4. As can be seen in the figure the rate of destruction of geosmin was significantly reduced when photocatalysis was conducted in the $\mathrm{D}_{2} \mathrm{O}$ solvent. Geosmin was still present after 25 minutes of photocatalytic treatment in $\mathrm{D}_{2} \mathrm{O}$ for all concentrations. In contrast to photocatalysis conducted in $\mathrm{H}_{2} \mathrm{O}$ under standard conditions where no geosmin was detectable after 25 minutes. The degradation profiles of geosmin in $\mathrm{D}_{2} \mathrm{O}$ displayed the same trend as geosmin degradation in $\mathrm{H}_{2} \mathrm{O}$ with respect to concentration. The rate of geosmin destruction was similar for 5,1 , and $0.5 \mu \mathrm{g}$ $\mathrm{ml}^{-1}$ concentrations, with only the $0.1 \mu \mathrm{g} \mathrm{ml}^{-1}$ geosmin concentration displaying a faster degradation rate. The typical loss of $30 \%$ geosmin after 25 minutes was observed under control conditions.

Figure 4 
To confirm the kinetic solvent isotope effect of $\mathrm{D}_{2} \mathrm{O}$ in the photocatalysis of geosmin, another cyanobacterial metabolite was selected for photocatalysis in $\mathrm{D}_{2} \mathrm{O}$, i.e. microcystin-LR (MC-LR). MC-LR was rapidly degraded in $\mathrm{H}_{2} \mathrm{O}$ and $\mathrm{D}_{2} \mathrm{O}$ respectively using $\mathrm{TiO}_{2}$ photocatalysis with a $\mathrm{D}_{50}$ of approximately 7 and 12 minutes. Again the rate of substrate destruction was reduced considerably when photocatalysis was conducted in $\mathrm{D}_{2} \mathrm{O}$ (Figure 5), confirming the kinetic solvent isotope effect for Hombikat K01/C.

Figure 5.

This observation confirms the role of the solvent in the photocatalytic reaction, since a kinetic solvent effect would only be demonstrated, through isotopic substitution, if the solvent is involved in the reaction [26]. To consider why the primary kinetic isotope effect for the destruction of both geosmin and microcystinLR results in a reduced rate for the photocatalytic destruction of both compounds it is important to consider the reactions that happen at the catalyst surface [27].

$$
\begin{gathered}
\mathrm{TiO}_{2}+\mathrm{hv} \rightarrow \mathrm{TiO}_{2}\left(\mathrm{e}_{\mathrm{cb}}^{-}+\mathrm{h}^{+}{ }_{\mathrm{vb}}\right) \\
\mathrm{h}^{+} \mathrm{vb}+\mathrm{OH}^{-} \text {,ads } \rightarrow \mathrm{OH}^{\cdot} \text {,ads } \\
\mathrm{OH}^{\cdot}{ }_{\text {,ads }}+\text { Reactant } \rightarrow \text { Oxidised products } \\
\mathrm{e}^{-\mathrm{tr}}+\mathrm{O}_{2, \text { ads }} \rightarrow \mathrm{O}_{2}{ }^{--} \\
\mathrm{O}_{2}{ }^{--}+\mathrm{H}^{+} \rightarrow \mathrm{HO}_{2} \cdot
\end{gathered}
$$

where $\mathrm{e}_{\mathrm{cb}}$ represents a conduction band (CB) electron and $\mathrm{h}^{+}{ }_{\mathrm{vb}}$ a positive hole in the valance band (VB) of the semiconductor. On changing to a deuterated 
solvent there will be a potential change in the rate of each of the reactions 2,3 and 5 which may ultimately have an influence on the rate of the destruction of the reacting molecule in the matrix. Of particular importance may be a reduced rate of oxidation of the adsorbed deuterated water (reaction 2) or a reduced rate of the OD radical attack on the substrate (reaction 3 ). It is however difficult to determine which step is likely to be rate limiting in this process.

The primary solvent isotope effect for the destruction of GSM using Hombikat $\mathrm{K} 01 / \mathrm{C} \mathrm{TiO}_{2}$ was calculated to be 1.61 (Table 1 ). This effect was verified by the photocatalysis of MC-LR in $\mathrm{D}_{2} \mathrm{O}$, where the primary solvent isotope effect was calculated to be 1.56 (Table 1) which is of a similar level to that observed for GSM. Robertson et al. [15] and Cunningham and Srijaranai [28] also reported primary solvent isotope effects for the destruction of microcystin-LR and isopropanol, respectively, using $\mathrm{P}-25 \mathrm{TiO}_{2}$. The primary solvent isotope effect of 3 reported by Robertson et al. [15] was similar to the effect of 3.3 reported by Cunningham and Srijaranai [28]. The results of both studies suggest that the formation of hydroxyl species is the main agent in substrate degradation and may be the rate limiting factor in the photocatalytic process. It was also proposed that the reduced rate of photocatalytic degradation was due to the lower quantum efficiency for the formation of ${ }^{-} \mathrm{OD}$ radicals on the $\mathrm{TiO}_{2}$ surface, resulting in a reduction of ${ }^{\bullet} \mathrm{OD}$ radicals on the $\mathrm{TiO}_{2}$ surface for subsequent attack on substrate molecules. Alternatively, the lower rate of oxidation may be due to the fact that - OD radicals have lowered oxidation potential when compared to ${ }^{\bullet} \mathrm{OH}$ radicals. It has been previously reported by Liu et al. [21] that the initial process in the 
photocatalytic destruction of microcystin-LR is the hydroxyl radical attack on the unsaturated bond of the ADDA group in the toxin. This was also reported to be the case in a subsequent study on the photocatalytic destruction of the pentaheptide toxin nodularin [29].

Table 1.

It is possible that the kinetic solvent isotope effect reported here for GSM (and MC-LR), which is appreciably lower than that found in the studies by Robertson et al. [15] and Cunningham and Srijaranai [28] is mediated via hydroxyl radicals generated from the subsequent reduction of the superoxide radical anion produced at the conduction band. $\mathrm{O}_{2}-$ is subsequently hydrated or deuterated by the solvent (reaction 5) [30]. This may be rate determining since $\mathrm{O}_{2}$ has to be generated at the conduction band prior to the interaction with the solvent and the subsequent formation of ${ }^{\bullet} \mathrm{OD}$ or $\bullet^{\bullet} \mathrm{OH}$ species (reactions 6 and 7 ).

$$
\begin{gathered}
\mathrm{HO}_{2}^{-}+\mathrm{HO}_{2}^{\cdot} \rightarrow \mathrm{H}_{2} \mathrm{O}_{2}+\mathrm{O}_{2} \\
\mathrm{H}_{2} \mathrm{O}_{2}+\mathrm{e}^{-} \mathrm{cb}
\end{gathered}
$$

Therefore the kinetic isotope effect could be caused by the interaction of the solvent with the superoxide species rather than by the attack of ${ }^{\bullet} \mathrm{OH}$ on GSM. Robertson et al. [15] proposed that if this was the case a similar kinetic solvent isotope effect should be observed no matter which substrate is being treated. The similarities in the kinetic solvent isotope effect for both GSM and MC-LR 
would suggest that formation of hydroxyl radicals generated via the superoxide radical anion produced at the conductance band is a rate determining step [31]. Hardly any isotopic effect would be expected if the reactions took place in the bulk aqueous phase i.e. isotopic effects close to unity have been experimentally determined and theoretically predicted for $\left.\bullet^{\circ} \mathrm{OH}_{\mathrm{aq}}\right|^{\bullet} \mathrm{OD}$ aq $[32-34]$

The difference in kinetic solvent isotope effect observed in this study (approx 1.5) compared to that reported by both Robertson and Cunningham (approx 3) can be explained by the fact that different photocatalyst materials were employed. An interesting observation is the fact that similar kinetic solvent isotope effects are observed for different substrate molecules on the same photocatalyst materials, i.e. approximately 3 for P-25 and approximately 1.5 for K01/C. This observation suggests that the interaction of the solvent with the photocatalyst and the rate of oxidation of the solvent is probably the rate determining step for the process rather that the rate of oxygen reduction as previously suggested by Gerischer [35]

Previously there have been reports of isotope studies on photocatalytic processes using isotopically labelled substrates rather than studies of the solvent isotope effect $[36,37]$. To the best of our knowledge, no other workers have investigated the kinetic solvent isotope effect with their particular photocatalytic systems. When more detailed studies of this effect are undertaken further elucidation of the kinetic isotope solvent effect will be possible. In particular 
investigations on other photocatalyst materials and looking at the oxidation of a range of different target molecules in both $\mathrm{H}_{2} \mathrm{O}$ and $\mathrm{D}_{2} \mathrm{O}$ should assist in a greater understanding of the mechanism of the photocatalytic oxidation process.

\section{Conclusion.}

A primary kinetic solvent isotope effect of approximately 1.5 has been observed for the photocatalytic oxidation of both geosmin and microcystin-LR on Hombikat $\mathrm{KO} 1 / \mathrm{C}$. This compares to a kinetic solvent isotope effect of approximately 3 which was previously reported for the destruction of both microcystin-LR and isopropanol on Degussa P25. It would appear the scale of kinetic solvent isotope effect is dependent on the nature of the photocatalyst employed. Furthermore the fact that the rate an isotopic effect is observed suggests that the photocatalytic process is occurring at the catalyst surface. The fact that the solvent isotope effect appears to be not influenced by the substrate would also suggest that the rate determining step for the photocatalytic process is the generation of the $\cdot \mathrm{OH}$ (or $-O D$ ) species at the valence band rather than oxygen reduction at the conductance band. 


\section{References}

[1].P.-E. Persson, Phycologia, 35 (1996) 168-171.

[2].P. Howgate, Aquaculture, 234 (2004) 155-181.

[3]. M. J.McGuire, Water Sci. Technol. 31 (1995) 1-8.

[4]. K. K. Schrader, A. M. Rimando, In: K. K. Schrader, A. M. Rimando (eds), Off-flavors in Aquaculture, ACS Symposium Series 848; American Chemical Society: Washington, DC, 2003, pp 1-12.

[5]. T. R. Hanson, T. R. In: K. K. Schrader, A. M. Rimando (eds), Off-flavors in Aquaculture, ACS Symposium Series 848; American Chemical Society: Washington, DC, 2003, pp 13-29

[6].W.W. Carmichael, Scientific American, 2, (1994), 64-72

[7]. L.A. Lawton, C. Edwards, K.A. Beattie, S. Pleasance, G.J. Dear and G.A. Codd, Nat. Toxins, 3 (1995) 50-57.

[8]. J. Dunn, Brit. Med. J., 313 (1996) 1183-1184.

[9]. K. Sivonen, W. W. Carmichael, M. Namikoshi, K. L. Rinehart, A. M. Dahlem, S. I. Niemela, Applied and Environ. Microbiol., 56, 1990,26502657.

[10]. K. Tsuji, T. Watanuki, F. Kondo, M. Wanatabe. S. Suzuki, H. Nakazawa, M. Suzuki, H. Uchida. K. Harada, Toxicon, 33, (1995), 16191631.

[11]. C. S. Reynolds, in: J.A. Callow (ed), Advances in Botanical Research, Academic Press, London, 1987, vol. 13, 63-143. 
[12]. K. Tsuji, S. Nalto, F. Kondo, N. Ishikawa, M.F. Watanabe, M.

Suzuki and K.-I. Harada, Environ. Sci. Technol. 28, (1994), 173-177.

[13]. L. A. Lawton, P. K. J. Robertson, Chem. Soc. Rev., 28 (1999) 217225.

[14]. P. K. J. Robertson, L. A. Lawton, B. Münch, J. Rouzade, Chem. Commun., 4 (1997) 393-395.

[15]. L. A. Lawton, P. K. J. Robertson, B. J. P. A. Cornish, M. Jaspars, J. Photoc. Photobio. A,116 (1998) 215-219.

[16]. L. A. Lawton, P. K. J. Robertson, B. J. P. A. Cornish, M. Jaspars, Environ. Sci. Technol., 33 (1999) 771-775.

[17]. B. J. P. A. Cornish, P. K. J. Robertson. L. A. Lawton, Appl. Catal. BEnviron., 25 (2000) 59-67

[18]. I. Liu, L. A. Lawton, B. Cornish, P. K. J. Robertson, J. Photochem, Photobiol, A, Chem, 148 (2002) 349-354.

[19]. L. A. Lawton, P. K. J. Robertson, B. J. P. A. Cornish, I. L. Marr, M. Jaspars, Journal of Catalysis, 213 (2003) 109-113.

[20]. L. A. Lawton, P. K. J. Robertson, R. F. Robertson, F. G. Bruce, Appl. Catal. B-Environ., 44 (2003) 9-13.

[21]. I. Liu, L. A. Lawton, P. K. J. Robertson, Environ. Sci. Technol., 37 (2003) 3214-3219.

[22]. E. Bellu, L. A. Lawton, P. K. J. Robertson, J. Adv. Oxid. Technol., $11(2008)$ 384-388. 
[23]. I. Liu, L. A. Lawton, D. W. Bahnemann, L. Liu, B. Proft and P. K. J. Robertson, Chemosphere, 76 (2009) 549-553.

[24]. D. Graham, H. Kisch, L. A. Lawton, P. K. J. Robertson, Chemosphere, 78 (2010) 1182-1185.

[25]. L.A. Lawton, C. Edwards, G.A. Codd, Analyst, 119 (1994) 15251530.

[26]. T. Hisatomi, K. Miyazaki, K. Takanabe, K. Maeda, J. Kubota, Y. Sakata, K, Domen, Chemical Physics Letters 486 (2010) 144-146. [27]. P. K. J. Robertson, D. W. Bahnemann, J. M. C. Robertson, F. Wood, in: P. Boule, D. W. Bahnemann, P. K.J Robertson (eds), Environmental Photochemistry Part II ,Springer-Verlag Berlin Heidelberg. 2005, pp 367-424.

[28]. J. Cunningham, S. Srijaranai, J. Photoc. Photobio. A. 43 (1988) 329-335.

[29]. I. Liu, L. A. Lawton, D. W. Bahnemann, P. K. J. Robertson, Appl. Catal. B-Environ., 60 (2005) 245-252

[30]. Y. Mao, C. Schoneich, K.D. Asmus, J. Phys. Chem., 95, (1991), 1080-1089.

[31]. R.B. Draper, M. A. Fox, Langmuir, 6, (1990), 1396-1402

[32]. G. Paraskevopoulos, W. S. Nip, Can. J. Chem. 58 (1980) 21462149

[33]. L. Yang, J-y Liu, Z.Li, J. Phys. Chem. A, 112 ( 2008) 6364-6372 
[34]. E. J. K. Nilsson, M. S. Johnson, C. J. Nielsen, J. Phys. Chem. A, 113 ( 2009) 1731-1739

[35]. H. Gerischer, A. Heller, J. Phys. Chem., 95 (1991) 5261-5267

[36]. Y-C Oh, Y. Bao, W. S. Jenks, J. Photoc. Photobio. A. 161 (2003) 69-77.

[37]. X. Li, W. S. Jenks, J. Am. Chem. Soc. 122 (2000) 11864-11870 


\section{Captions for figures.}

Figure 1. Structure of Geosmin.

Figure 2. Structure of microcystin-LR where L-Leu is L-Leucine, D-Me-Asp is Derythro- $\beta$-methylaspartic acid, L-Arg is L-arginine, Adda is (2S, 3S, 8S, 9S)-3amino-9-methoxy-2,6,8-trimethyl-10-phenyldeca-4(E),6(E)-dienoic acid, D-Glu is D-glutamic acid and Mdha is $N$-Me-dehydroalanine.

Figure 3. Photocatalytic reactor used for decomposition reactions with arrows indicating direction of air flow. The main body of the reactor was constructed from glass and all tubing was Teflon.

Figure 4. The photocatalytic destruction of different geosmin concentrations, 1 $\mu \mathrm{g} \mathrm{ml}^{-1}(\neg-), 0.5 \mu \mathrm{g} \mathrm{ml}^{-1}(\multimap-), 0.1 \mu \mathrm{g} \mathrm{ml}^{-1}(-\square)$, and $5 \mu \mathrm{g} \mathrm{ml}^{-1}(\neg)$, using Hombikat K01/C, in $\mathrm{D}_{2} \mathrm{O}$ (a) and Milli-Q (b). Photocatalysis monitored by GCMS. Bars equivalent to one standard deviation $(n=2)$.

Figure 5. Destruction of MC-LR by $\mathrm{TiO}_{2}$ photocatalysis in Milli-Q $(\neg)$ and $\mathrm{D}_{2} \mathrm{O}$ $(\rightarrow-)$. Photocatalysis monitored by HPLC. Bars equivalent to one standard deviation $(n=2)$.

Table 1. Kinetic isotope effect based on the photocatalytic destruction of GSM and MC-LR in two different solvents. 


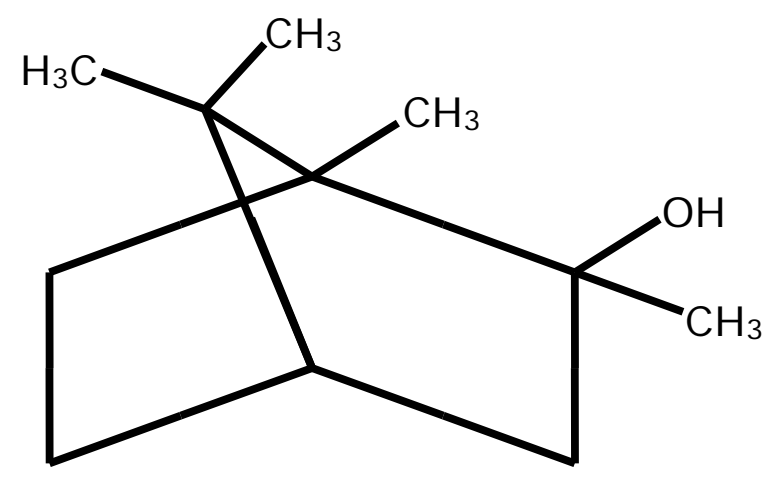

Figure 1. 


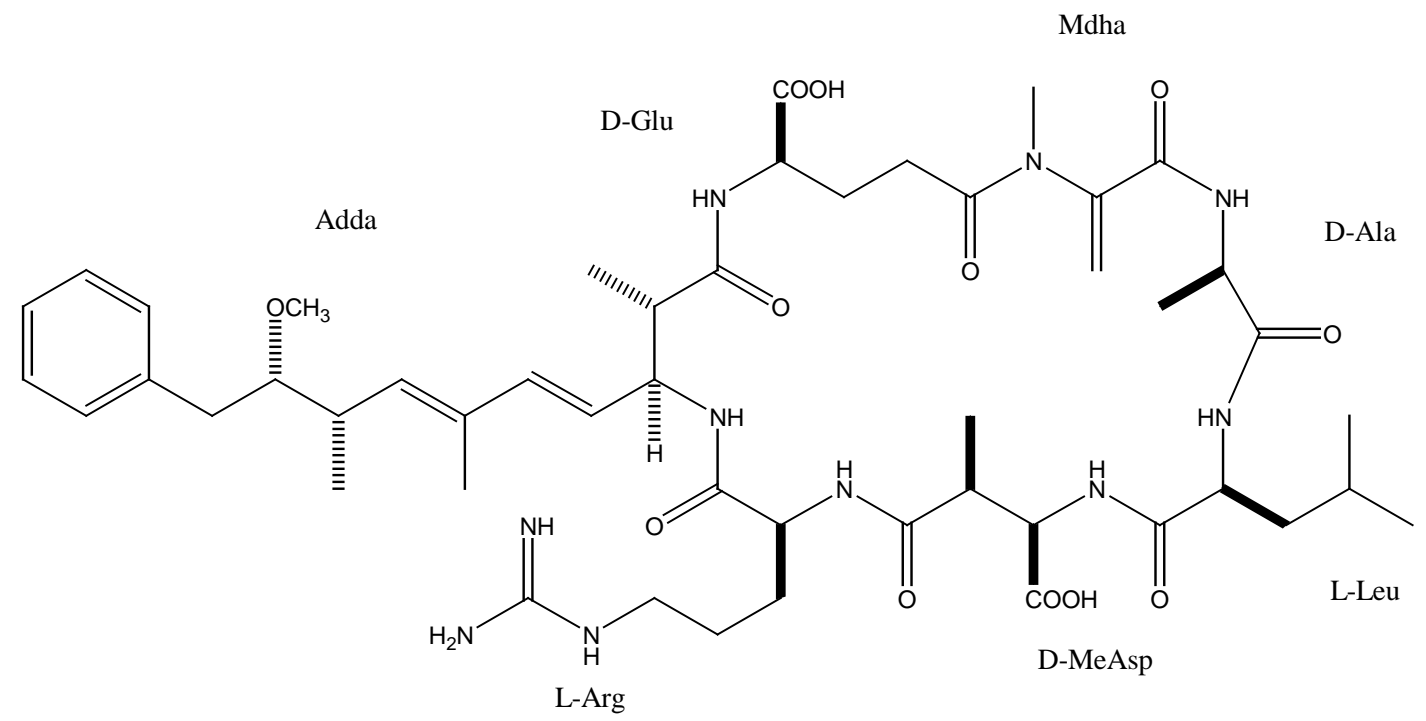

Figure 2. 


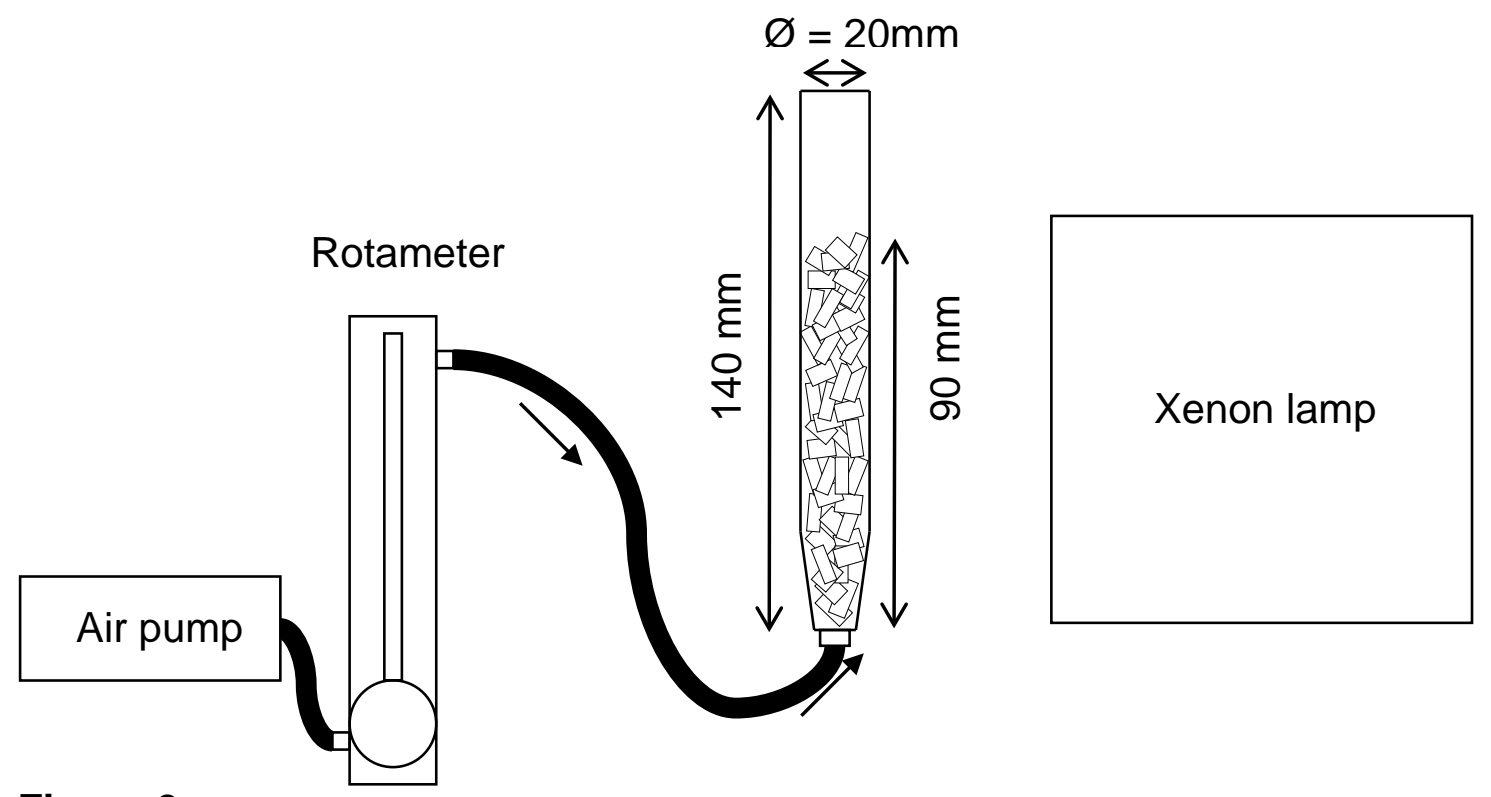

Figure 3. 


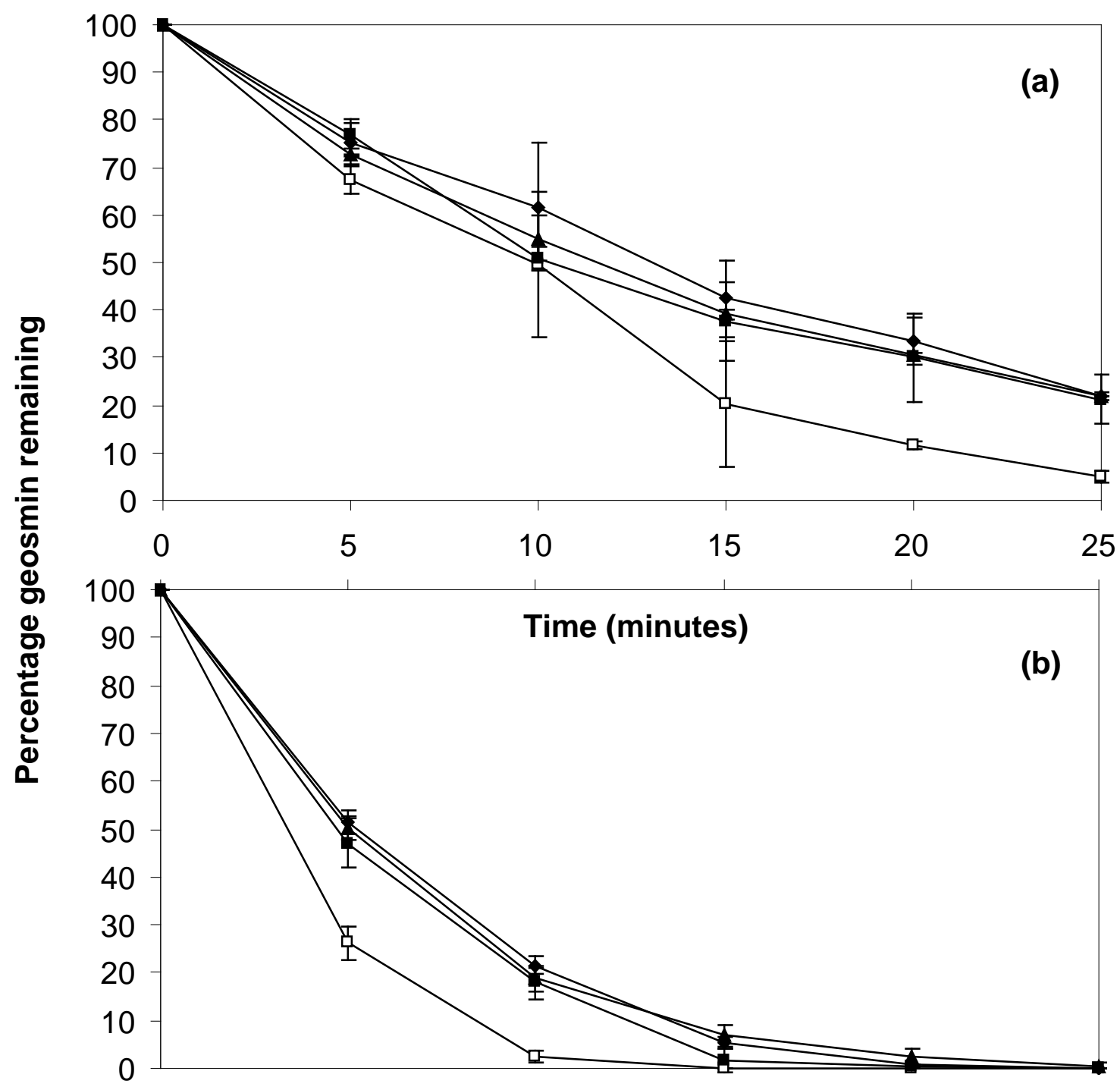

Figure 4. 


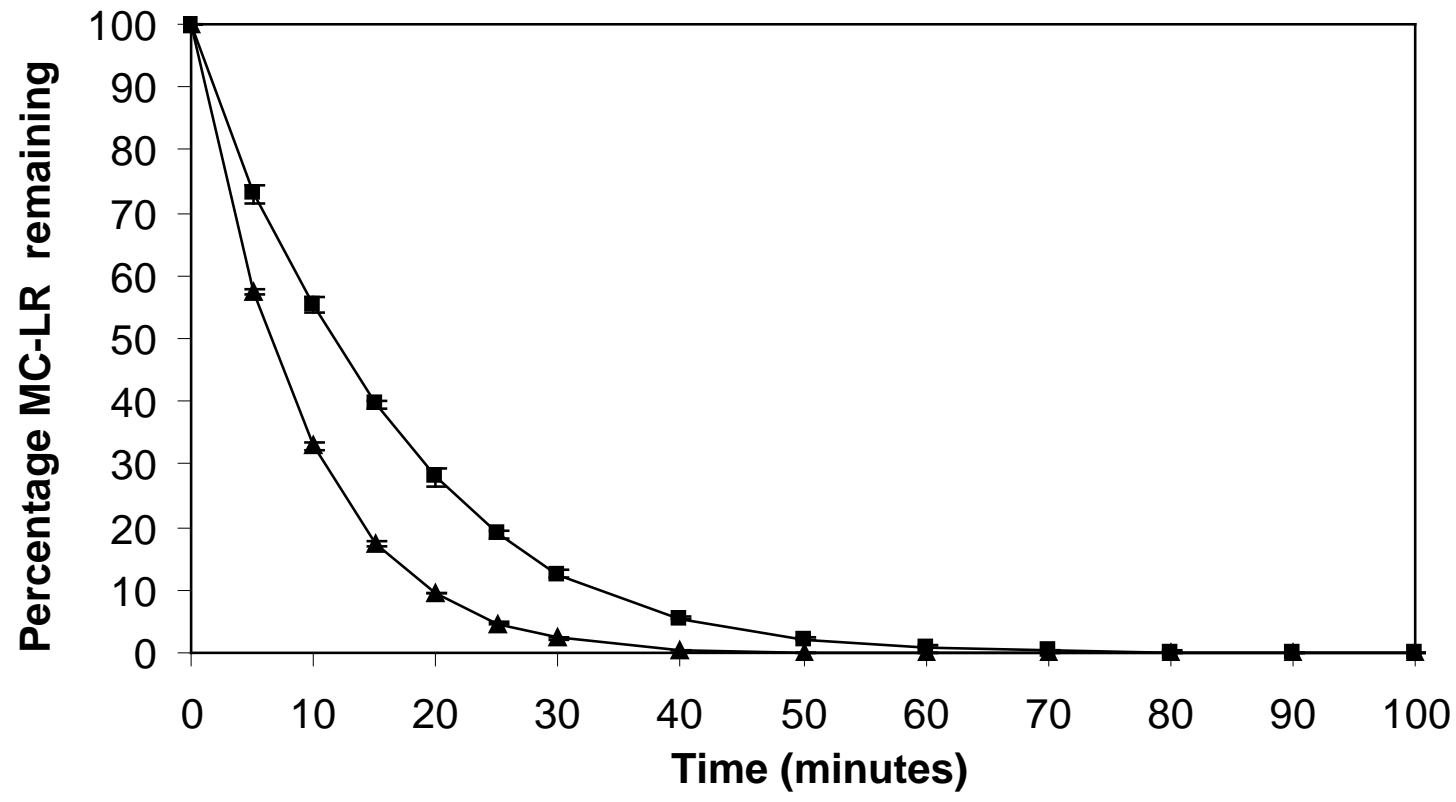

Figure 5.

\begin{tabular}{|c|c|c|c|c|}
\cline { 2 - 5 } \multicolumn{1}{c|}{} & \multicolumn{2}{c|}{ GSM } & \multicolumn{2}{c|}{ MC-LR } \\
\hline Solvent & $\boldsymbol{k}\left(\mu \mathrm{M} \mathrm{min}^{-1}\right)$ & $\begin{array}{c}\text { Relative } \\
\text { Rate }\end{array}$ & $\boldsymbol{k}\left(\mu \mathrm{M} \mathbf{m i n}^{-1}\right)$ & $\begin{array}{c}\text { Relative } \\
\text { Rate }\end{array}$ \\
\hline $\mathrm{H}_{2} \mathrm{O}$ & 1.56 & 1.0 & 8.55 & 1.0 \\
\hline $\mathrm{D}_{2} \mathrm{O}$ & 0.97 & 0.62 & 5.44 & 0.64 \\
\hline
\end{tabular}

Table 1. 